\title{
Monitoramento da contaminação por elementos traço em ostras comercializadas em Recife, Pernambuco, Brasil
}

\author{
Monitoring of trace elements in oysters \\ marketed in Recife, Pernambuco, Brazil
}

André Dias Cavalcanti 1

1 Centro Regional de Ciências Nucleares, Comissão Nacional de Energia Nuclear. Rua Cônego Barata 999, Recife, PE 52110-120, Brasil. cquimica@cnen.gov.br
Abstract Samples of oysters marketed in Recife, Pernambuco, Brazil, were monitored for the concentration of trace elements ( $\mathrm{Hg}, \mathrm{Zn}, \mathrm{Fe}, \mathrm{Cu}$, and $\mathrm{Mn}$ ) for one year (from March 2001 to February 2002). Mercury was the principal contaminant found in oysters and the element posing the greatest public health risk. Mercury levels in oysters reached $551.12 \mu \mathrm{g} / \mathrm{kg}$ (wet weight). These values suggest that oyster consumption should be restricted, especially among communities that gather them as a subsistence activity, as well as by children and pregnant women. Evaluation of mercury concentration in seafood is an important factor for assessing the risk of contamination among individuals who are not occupationally exposed.

Key words Oysters; Mercury; Atomic Absorption; Chemical Contamination; Environmental Pollution

Resumo Amostras de ostras comercializadas em Recife, Pernambuco, Brasil, foram monitoradas em relação ao conteúdo de elementos traço ( $\mathrm{Hg}, \mathrm{Zn}, \mathrm{Fe}$, Cu e Mn) durante o período de um ano (março/2001 a fevereiro/2002). Mercúrio foi o principal contaminante encontrado nas ostras e o elemento que apresenta maior risco à saúde pública. Foram encontrados valores de concen-

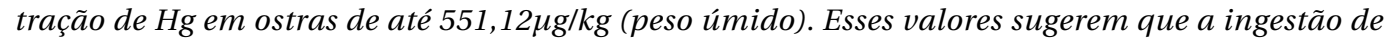
ostras deve ser feita com restrições, principalmente, pela população que vive de sua coleta como forma de subsistência, por crianças, e mulheres grávidas. A avaliação dos níveis de mercúrio em frutos do mar é um importante fator para avaliar o risco de contaminação por mercúrio em pessoas não ocupacionalmente expostas.

Palavras-chave Ostras; Mercúrio; Absorção Atômica; Contaminação Química; Poluição Ambiental 


\section{Introdução}

A ostra é considerada um alimento de grande valor nutriticional, principalmente por ser uma rica fonte protéica e pelo seu alto teor de micronutrientes. É um importante constituinte da dieta das populações litorâneas em todo o mundo, sendo seu consumo um hábito alimentar diário em muitas comunidades de pescadores. O canal de Santa Cruz é o estuário de maior produtividade pesqueira de Pernambuco e responsável pela quase totalidade da produção de ostras do Estado. Em 1998, foram coletadas 525,3t de ostras nesse estuário (IBAMA, 1999). Além de contribuir na composição da alimentação da população local, a ostra capturada abastece também a Região Metropolitana do Recife. No entanto, estudos prévios mostraram que o canal de Santa Cruz recebe significativa contribuição antropogênica de mercúrio (Meyer, 1996), apresentando um histórico de contaminação que poderia, via cadeia alimentar, alcançar o homem colocando em risco sua saúde.

A avaliação dos níveis de metais pesados em alimentos consumidos localmente é o primeiro passo para a avaliação de riscos à população humana devido à contaminação ambiental por esses metais (Niencheski et al., 2001). Tanto elementos essenciais quanto não essenciais são tóxicos aos organismos vivos, quando presentes em altas concentrações. Muitos metais pesados podem ser acumulados no organismo marinho até níveis que podem ser prejudiciais às pessoas que os consomem (Goldberg et al., 1983). A presença de metais pesados em peixes, crustáceos e ostras está associada a riscos em relação à saúde pública porque estes contaminantes podem acumular-se nos homens se estes organismos forem consumidos (Jones et al., 2000). O acúmulo de metais pesados nas ostras deve-se à capacidade limitada destes organismos de metabolizar e depurar contaminantes absorvidos, em comparação com muitas outras espécies (Farrington et al., 1983).

A indústria de cloro e soda cáustica tem sido reconhecida como a fonte mais importante de lançamento de mercúrio no ambiente aquático (Inácio, 1998). O mercúrio é um dos elementos não essenciais mais perigosos à saúde humana. Para diminuir seu impacto na saúde e no meio ambiente, o Governo Federal criou a Lei 9.976 que proíbe a instalação de novas indústrias químicas para produção de cloro usando células de mercúrio (Brasil, 2000). Entretanto, indústrias já instaladas têm um histórico de lançamento de grandes quantidades de resíduos e, muitas vezes, funcionam sem a devida fiscalização dos órgãos ambientais. O desapa- relhamento e a falta de pessoal desses órgãos, na maioria das vezes, são os fatores preponderantes para dificultar a realização do controle dos níveis de rejeitos lançados por estas indústrias no ambiente, de acordo com os limites previstos na legislação ambiental vigente.

O mercúrio lançado com os rejeitos industriais acumula-se, primariamente, nos sedimentos que podem servir como uma fonte para a cadeia alimentar marinha (Gagnon \& Fisher, 1997). Ele bioacumula e biomagnifica na cadeia alimentar aquática podendo ter efeitos adversos no organismo humano, incluindo efeitos neurológicos, reprodutivos, comportamentais e toxicidade direta, em altas doses. Crianças e fetos possuem um maior risco em relação à contaminação por mercúrio (USEPA, 1995). O consumo de frutos do mar é considerado a principal fonte de absorção de mercúrio por pessoas não ocupacionalmente expostas (USEPA, 1997). O metilmercúrio (MeHg), formado a partir da biometilação do mercúrio no ambiente aquático, como muitos outros poluentes ambientalmente persistentes que se acumulam em peixes, é neurotóxico, podendo afetar a performance motora e visual (Mergler, 2002). Os sintomas de envenenamento provocados por MeHg são: degeneração do sistema nervoso com perda da visão, audição, fala, controle motor, fraqueza muscular e comportamento anormal. A neurotoxicidade deste composto tem sido a principal preocupação em relação ao desenvolvimento dos fetos expostos durante a gravidez. Em muitos casos, crianças nascidas de mães expostas, principalmente durante o segundo trimestre da gravidez, mostraram danos neurológicos: demora em andar, falar, crescer e no desenvolvimento mental normal (WHO, 2002a).

O zinco, por outro lado, tem um importante papel no crescimento, desenvolvimento e função de todas as células vivas, sendo um micronutriente essencial encontrado em abundância nas ostras. Atua como co-fator em várias metaloenzimas e proteínas reguladoras, incluindo a biossíntese e reparo do DNA e RNA (Brzóska \& Jakoniuk, 2001). Ferro, manganês e cobre são micronutrientes essenciais ao homem e participam de importantes processos metabólicos.

Este trabalho teve como objetivo realizar um monitoramento dos níveis de elementos traço (Hg, Mn, Zn, Cu e Fe), em ostras comercializadas na praia de Boa Viagem, Recife (Pernambuco), durante o período de março de 2001 a fevereiro de 2002, a fim de se avaliar os riscos e os benefícios que poderiam estar associados a seu consumo. 


\section{Metodologia}

Amostras de ostras foram compradas de vendedores ambulantes na praia de Boa Viagem (Recife, Pernambuco) e em Itapissuma (Pernambuco). Também foram adquiridas amostras de ostras com pescadores locais em Tejucupapo (Goiana, Pernambuco) e Acaú (Pitimbu, Paraíba), fronteira com Pernambuco. As amostras adquiridas foram transportadas para o laboratório e guardadas sob refrigeração a $-20^{\circ} \mathrm{C}$ até o momento da análise. Posteriormente, as ostras foram medidas com paquímetro e selecionadas de acordo com o tamanho de suas conchas $(4,0-8,0 \mathrm{~cm})$. Em seguida, foram abertas com a ajuda de espátula de aço inox e a parte comestível foi lavada com água Milli-Q (18,2M $2 . \mathrm{cm})$, e retirada da concha utilizando espátula de porcelana. A seguir, as amostras de ostras foram transferidas para béqueres de vidro previamente descontaminados, pesadas e, em seguida, liofilizadas (Savant - micromodulyo). Após a liofilização, foram trituradas com grau e pistilo de porcelana até a homogeneização. Cerca de $0,5 \mathrm{~g}$ de cada amostra foi pesado em balança analítica e digeridas em forno de microondas fechado (CEM Corporation - Mars 5). A digestão, no forno de microondas, foi feita utilizando tubos de Teflon ${ }^{\circledR}$ previamente descontaminados e com a adição de $10 \mathrm{~mL}$ de $\mathrm{HNO}_{3}$ padrão subboiling. Após o término da digestão, as amostras foram diluídas a cerca de $50,0 \mathrm{~mL}$.

A determinação da concentração de mercúrio nas amostras de ostras foi realizada por espectrofotometria de absorção atômica (Varian 220-FS), utilizando a técnica de vapor frio de mercúrio (VGA 77), com a utilização de agente redutor solução $0,3 \%$ de $\mathrm{NaBH}_{4}$ em meio básico $(\mathrm{NaOH}-0,5 \%)$. As concentrações de cobre, ferro, zinco e manganês foram determinadas utilizando espectrofotometria de absorção atômica no modo chama ar/acetileno e calibração externa com base em padrões monoelementares (Merck), $1.000 \mu \mathrm{g} / \mathrm{g}$.

Todas as amostras foram analisadas em triplicatas. Os brancos das amostras foram pre- parados com os mesmos reagentes e nas mesmas condições de mineralização das amostras. Amostras de material de referência certificado SRM 2976 - Mussel Tissue (certificação do Hg, Zn, Fe e Cu) e SRM 1577b - Bovine Liver (certificação do Mn) da NIST foram submetidas às mesmas condições das amostras e apresentaram resultados concordantes com os certificados (Tabela 1).

O limite de detecção do método para cada elemento químico estudado foi estabelecido como sendo três vezes o desvio padrão do branco. Os valores obtidos foram: $\mathrm{Hg}-0,3 \mu \mathrm{g} / \mathrm{kg} ; \mathrm{Zn}-$

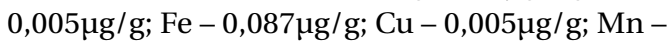
$0,015 \mu \mathrm{g} / \mathrm{g}$.

Os dados de concentração obtidos em peso seco foram convertidos em peso úmido e comparados com os valores limites estabelecidos pelas agências reguladoras internacionais. Esta conversão foi feita dividindo o valor obtido em peso seco por 6,8 que é o valor indicado para a espécie Crassostrea (Wright et al., 1985).

\section{Resultados e discussão}

A comparação entre a concentração de elementos traço nas amostras de ostras estudadas, os dados estatísticos de produção de pescado no estado, o perfil industrial da região (FIEPE, 1998), e a confirmação da origem das ostras, por parte dos vendedores, indicam que a origem das amostras de ostras adquiridas em Boa Viagem é o canal de Santa Cruz (Itapissuma).

De acordo com os dados estatísticos disponíveis, em 1998, cerca de 99,98\% das ostras capturadas no Estado de Pernambuco foram provenientes do canal de Santa Cruz (Itapissuma) (IBAMA, 1999). Apenas cerca de 0,02\% das ostras são provenientes de Goiana.

Em relação à concentração dos elementos traço nas amostras estudadas, o principal indicador refere-se à concentração de mercúrio, que é alta nas ostras do canal de Santa Cruz (Itapissuma) bem como nas de Boa Viagem (Tabela 2). Concentrações altas de mercúrio

Tabela 1

Análise do material de referência certificado SRM 2976 - mussel tissue (Cu, Zn, Fe e Hg) e SRM 1577b - bovine liver (Mn).

\begin{tabular}{lcccc}
\hline Amostra & $\mathrm{Cu}(\mu \mathrm{g} / \mathrm{g})$ & $\mathrm{Fe}(\boldsymbol{\mu g} / \mathbf{g})$ & $\mathrm{Mn}(\boldsymbol{\mu g} / \mathbf{g})$ & $\mathrm{Zn}(\boldsymbol{\mu g} / \mathbf{g})$ \\
\hline SRM (2976) certificado & $4,02 \pm 0,33$ & $171,00 \pm 4,90$ & $10,50 \pm 1,50$ & $137,00 \pm 13,00$ \\
SRM experimental & $4,04 \pm 0,10$ & $176,70 \pm 8,40$ & $9,05 \pm 0,40$ & $140,00 \pm 1,10$ \\
\hline
\end{tabular}


em organismos marinhos são características de ambientes impactados por contaminação antrópica. A contaminação das ostras provenientes do canal de Santa Cruz por mercúrio é devido à existência de uma fábrica de cloro e soda cáustica, que utiliza eletrodos de mercúrio e despeja seus rejeitos no rio Botafogo, um dos principais rios que deságuam no canal.

As ostras provenientes de Goiana também apresentaram valores altos de concentração de mercúrio (Tabela 2). Estes valores ocorrem devido ao fato de uma parte das ostras comercializadas em Goiana serem provenientes do vilarejo de Tejucupapo, que se localiza às margens do estuário formado pelo rio Itapessoca, que tem comunicação hídrica com o canal de Santa Cruz. No entanto, a distância de Tejucupapo em relação à praia de Boa Viagem (Recife) e a dificuldade de transporte é um forte inibidor da comercialização de ostras dessa região em Boa Viagem, visto que a mesma é feita pelos próprios catadores ou seus familiares, de forma individualizada, como vendedores ambulantes. As mesmas restrições existem em relação à comercialização das ostras capturadas em Acaú (Paraíba), em Boa Viagem.

A concentração de cobre nas ostras provenientes de Acaú apresentou um valor cerca de três vezes maior do que a encontrada nas provenientes de outros locais estudados. As concentrações de zinco, ferro e manganês não apresentaram diferenças significativas entre os quatro locais estudados (Tabela 2).

O limite máximo de tolerância para o mercúrio, expresso em peso úmido, em frutos do mar, estabelecido por agências americanas é de $1.000 \mu \mathrm{g} / \mathrm{kg}$. Muitos outros países têm ajustado limites de tolerância mais baixos que os Estados Unidos. Austrália e Canadá, por exemplo, fixaram o limite de tolerância em 500 $\mathrm{gg} / \mathrm{kg}$ (Francesconi et al., 1997). No entanto, existe risco po- tencial para a saúde pública, em especial para as populações em regime de subsistência, quando a concentração de mercúrio em organismos marinhos está na ordem de $60-100 \mu \mathrm{g} / \mathrm{kg}$ (peso úmido) (Kawaguchi, et al., 1999). Os motivos da causa deste risco se deve ao fato da meia vida biológica do mercúrio ser muita longa, dele ser lentamente excretado, podendo ser bioacumulado (WHO, 2002b), e devido à neurotoxicidade do MeHg. O valor médio da concentração de mercúrio total (Tabela 3) nas ostras monitoradas neste estudo foi de 197,65 $\pm 135,27 \mu \mathrm{g} / \mathrm{kg}$ (peso úmido), situando-se abaixo dos valores do limite máximo permitido e acima dos valores de risco potencial, de forma que seu consumo deve ser cuidadosamente controlado, principalmente nas populações de maior risco. Esta recomendação é ainda mais pertinente quando se considera a ocorrência de concentração de mercúrio de até $551,12 \mu \mathrm{g} / \mathrm{kg}$ (peso úmido), referente ao mês de abril de 2001 (Tabela 3), superando o limite máximo de tolerância de $500 \mu \mathrm{g} / \mathrm{kg}$.

As comunidades nas quais se encontram os catadores de ostras estão, em sua maior parte, próximas da linha da pobreza absoluta. O quadro de desnutrição em que geralmente vivem aumenta os riscos da contaminação por mercúrio. Por afetar o desenvolvimento neurológico, crianças e mulheres grávidas devem restringir ou mesmo evitar este tipo de alimento, pois caso ele esteja contaminado por mercúrio há sérios riscos de comprometer o desenvolvimento neurológico de fetos e crianças (USEPA, 1995).

A concentração média de zinco nas ostras monitoradas foi de $196,20 \pm 106,10 \mu \mathrm{g} / \mathrm{g}$ (peso úmido) (Tabela 3). O limite de tolerância para o zinco em ostras é de 1.000 $\mu \mathrm{g} / \mathrm{g}$ (ANZFA, 1996). A concentração observada nas ostras monitoradas em Boa Viagem apresentou valores inferiores a esta recomendação. A presença significativa de zinco nas ostras é um dos fatores que au-

Concentração de elementos traço (peso seco*) das ostras provenientes de Boa Viagem, canal de Santa Cruz, Tejucupapo (Goiana) e Acaú

\begin{tabular}{|c|c|c|c|c|c|}
\hline Amostra & $\mathrm{Cu}(\mu \mathrm{g} / \mathrm{g})$ & $\mathrm{Fe}(\mu \mathrm{g} / \mathrm{g})$ & $M n(\mu g / g)$ & $\mathrm{Zn}(\mu \mathrm{g} / \mathrm{g})$ & $\mathrm{Hg}(\mu \mathrm{g} / \mathrm{kg})$ \\
\hline Boa Viagem (média) & $15,19 \pm 4,50$ & $300,69 \pm 66,06$ & $20,58 \pm 4,75$ & $1.334,20 \pm 721,47$ & $1.344,01 \pm 919,84$ \\
\hline Boa Viagem (range) & $7,70-21,50$ & $190,50-400,80$ & $4,60-26,80$ & $782,50-3.415,60$ & $135,90-3.747,60$ \\
\hline Canal de Santa Cruz & $16,50 \pm 1,30$ & $234,90 \pm 12,30$ & $35,20 \pm 3,50$ & $1.046,30 \pm 54,90$ & $814,10 \pm 48,30$ \\
\hline Tejucupapo (Goiana) & $7,80 \pm 0,30$ & $236,20 \pm 9,50$ & $13,10 \pm 0,60$ & $636,60 \pm 23,50$ & $923,90 \pm 56,00$ \\
\hline Acaú (Pitimbu) & $54,70 \pm 3,30$ & $287,30 \pm 18,60$ & $25,50 \pm 1,30$ & $891,30 \pm 61,10$ & $400,30 \pm 68,90$ \\
\hline
\end{tabular}

* A conversão de peso seco para peso úmido deve ser feita dividindo o valor obtido em peso seco por 6,8 (fator utilizado para a espécie Crassostrea). 
Tabela 3

Concentração de elementos traço (peso seco*) em ostras compradas em Boa Viagem (Recife, Pernambuco) no período de março de 2001 a fevereiro de 2002.

\begin{tabular}{|c|c|c|c|c|c|}
\hline Amostra & $\mathrm{Cu}(\mu \mathrm{g} / \mathrm{g})$ & $\mathrm{Fe}(\mu \mathrm{g} / \mathrm{g})$ & $M n(\mu g / g)$ & $\mathrm{Zn}(\mu \mathrm{g} / \mathrm{g})$ & $\mathrm{Hg}(\mu \mathrm{g} / \mathrm{kg})$ \\
\hline Março (2001) & $7,70 \pm 0,33$ & $288,03 \pm 14,00$ & $21,41 \pm 0,96$ & $1.826,53 \pm 98,00$ & $135,96 \pm 20,30$ \\
\hline Abril (2001) & $15,62 \pm 2,32$ & $245,24 \pm 40,40$ & $15,65 \pm 3,97$ & $1.347,43 \pm 24,30$ & $3.747,61 \pm 10,30$ \\
\hline Maio (2001) & $20,14 \pm 1,96$ & $304,04 \pm 24,50$ & $23,11 \pm 2,04$ & $1.381,60 \pm 49,10$ & $469,52 \pm 11,90$ \\
\hline Junho (2001) & $19,31 \pm 0,92$ & $365,33 \pm 5,80$ & $26,79 \pm 3,61$ & $1.257,53 \pm 68,10$ & $1.338,94 \pm 28,20$ \\
\hline Julho (2001) & $12,75 \pm 0,55$ & $258,44 \pm 15,50$ & $19,30 \pm 0,94$ & $863,03 \pm 35,30$ & $1.254,01 \pm 25,10$ \\
\hline Agosto (2001) & $12,59 \pm 0,37$ & $334,71 \pm 19.50$ & $22,36 \pm 1,44$ & $782,46 \pm 53,50$ & $1.175,73 \pm 1,70$ \\
\hline Setembro (2001) & $10,11 \pm 0,36$ & $400,83 \pm 25,40$ & $11,04 \pm 0,67$ & $3.415,60 \pm 337,00$ & $1.465,93 \pm 24,30$ \\
\hline Outubro (2001) & $19,94 \pm 1,21$ & $243,40 \pm 2,80$ & $24,87 \pm 1,10$ & $919,63 \pm 18,90$ & $1.745,70 \pm 47,90$ \\
\hline Novembro (2001) & $11,54 \pm 0,96$ & $398,43 \pm 15,00$ & $22,91 \pm 0,64$ & $1.260,94 \pm 44,40$ & $1.616,41 \pm 64,30$ \\
\hline Dezembro (2001) & $17,88 \pm 0,70$ & $245,68 \pm 12,80$ & $15,53 \pm 1,65$ & $830,83 \pm 92,40$ & $1.125,36 \pm 74,00$ \\
\hline Janeiro (2002) & $13,24 \pm 0,71$ & $333,56 \pm 23,60$ & $18,19 \pm 0,47$ & $924,61 \pm 80,30$ & $1.646,65 \pm 75,80$ \\
\hline Fevereiro (2002) & $21,50 \pm 1,09$ & $190,53 \pm 28,10$ & $25,77 \pm 0,62$ & $1.200,03 \pm 126,90$ & $406,24 \pm 36,40$ \\
\hline Média (peso seco) & $15,19 \pm 4,50$ & $300,69 \pm 67,06$ & $20,58 \pm 4,75$ & $1.334,20 \pm 721,47$ & $1.344,01 \pm 919,84$ \\
\hline Média (peso úmido) & $2,23 \pm 0,66$ & $44,21 \pm 9,86$ & $3,03 \pm 0,70$ & $196,20 \pm 106,10$ & $197.65 \pm 135,27$ \\
\hline
\end{tabular}

* A conversão de peso seco para peso úmido deve ser feita dividindo o valor obtido em peso seco por 6,8 (fator utilizado para a espécie Crassostrea).

mentam seu valor nutritivo em relação a outras fontes alimentares. O consumo de ostras pode, desta forma, contribuir para a melhoria do estado nutricional dos indivíduos na medida em que repõe os estoques de zinco necessários ao bom funcionamento do organismo.

Os valores da concentração de cobre nas ostras monitoradas foram relativamente baixos, não indicando fontes significativas de contaminação. O valor médio da concentração de cobre nas ostras foi de 2,23 $\pm 0,66 \mu \mathrm{g} / \mathrm{g}$ (peso úmido). As concentrações médias encontradas para o ferro e para o manganês foram, respectivamente, 44,21 $\pm 9,86 \mu \mathrm{g} / \mathrm{g}$ (peso úmido) $\mathrm{e}$ $3,03 \pm 0,70 \mu \mathrm{g} / \mathrm{g}$ (peso úmido) (Tabela 3 ). Os valores encontrados não implicam os riscos imediatos à saúde, de forma que, em relação ao suprimento das necessidades diárias destes elementos, o consumo de ostras é recomendado.

A variabilidade interanual da concentração dos elementos estudados nas ostras apresentou um comportamento praticamente aleatório (Tabela 3). A variabilidade nas concentrações encontradas dos elementos estudados pode estar relacionada, tanto com os diferentes locais de coleta das ostras ao longo do estuário, quanto com a variação da carga de poluentes lançados pelas fábricas no estuário ao longo do ano. A variação observada não indicou a ocorrência de efeitos sazonais bem definidos.

A variação ocorrida devido aos diferentes pontos de coleta das ostras pode ser explicada em função da extensão do canal de Santa Cruz $(22 \mathrm{~km})$ e aos diversos rios que nele deságuam (rio Botafogo, rio Arataca, rio Igarassu, rio Tabatinga, entre outros). Como o estuário tem uma extensão considerável, é de se esperar que haja gradientes de concentração ao longo de sua extensão. Além disso, também poderia estar contribuindo para este padrão aleatório de variação, parâmetros como tamanho e idade das ostras (Tabela 4), além da variação dos parâmetros físico-químicos das águas do estuário ao longo do ano.

Testes de correlação $(\mathrm{p}<0,05)$ entre as variações da concentração dos elementos, do tamanho e da massa das amostras de ostras não mostraram a ocorrência de correlação significativa entre nenhuma dessas variáveis (Tabela 5).

\section{Conclusão}

A ostra é um alimento de grande valor nutritivo e, por isso, não deveria ser retirada da dieta, mas o consumo limitado de ostras e de outros frutos do mar provenientes de locais poluídos é recomendado. Essa recomendação é, ainda, mais fortemente encorajada no caso de ambientes contaminados por mercúrio, devido ao seu efeito neurotóxico.

De uma perspectiva da saúde pública, crianças, mulheres grávidas e a população que vive de subsistência estão sujeitas a maiores ris- 
Dados das amostras de ostras analisadas.

\begin{tabular}{|c|c|c|c|c|}
\hline $\begin{array}{l}\text { Período } \\
\text { de coleta }\end{array}$ & $\begin{array}{l}\text { Tamanho } \\
\text { médio }(\mathrm{cm})\end{array}$ & $\begin{array}{c}\text { Amplitude } \\
\text { (cm) }\end{array}$ & $\begin{array}{l}\text { Indivíduos } \\
\text { (n) }\end{array}$ & $\begin{array}{c}\text { Massa média } \\
\text { (g) }\end{array}$ \\
\hline Março & 5,4 & $4,5-6,5$ & 19 & 3,9 \\
\hline Abril & 6,2 & $4,5-7,0$ & 14 & 3,8 \\
\hline Maio & 6,3 & $5,6-7,4$ & 16 & 3,8 \\
\hline Junho & 5,7 & $4,7-7,3$ & 18 & 3,0 \\
\hline Julho & 5,4 & $4,6-6,6$ & 18 & 3,3 \\
\hline Agosto & 6,5 & $5,1-8,0$ & 14 & 5,3 \\
\hline Setembro & 6,1 & $5,0-7,6$ & 15 & 2,8 \\
\hline Outubro & 5,7 & $4,0-7,7$ & 15 & 2,4 \\
\hline Novembro & 5,9 & $4,3-8,0$ & 15 & 3,1 \\
\hline Dezembro & 5,9 & $5,1-6,7$ & 18 & 3,2 \\
\hline Janeiro & 5,7 & $4,2-8,0$ & 20 & 4,1 \\
\hline Fevereiro & 5,6 & $4,4-7,4$ & 18 & 3,2 \\
\hline Canal Santa Cruz & 5,1 & $4,2-6,0$ & 21 & 2,8 \\
\hline Tejucupapo & 6,6 & $6,5-7,6$ & 13 & 5,3 \\
\hline Praia de Acaú & 5,3 & $4,1-6,7$ & 20 & 2,7 \\
\hline
\end{tabular}

Tabela 5

Correlação $(p<0,05)$ entre as concentrações dos elementos traço estudados, tamanho e massa das amostras de ostras.

\begin{tabular}{lccccccc}
\hline Variável & $\mathbf{H g}$ & $\mathbf{Z n}$ & $\mathbf{C u}$ & $\mathbf{F e}$ & Mn & Tamanho & Massa \\
\hline $\mathrm{Hg}$ & 1,00 & $-0,4$ & $-0,00$ & 0,03 & $-0,39$ & 0,31 & $-0,04$ \\
$\mathrm{Zn}$ & $-0,4$ & 1,00 & $-0,42$ & 0,46 & $-0,51$ & 0,11 & $-0,28$ \\
$\mathrm{Cu}$ & $-0,00$ & $-0,42$ & 1,00 & $-0,50$ & 0,48 & 0,07 & $-0,33$ \\
$\mathrm{Fe}$ & 0,03 & 0,46 & $-0,50$ & 1,00 & $-0,16$ & 0,30 & 0,07 \\
$\mathrm{Mn}$ & $-0,39$ & $-0,51$ & 0,48 & $-0,16$ & 1,00 & $-0,23$ & $-0,02$ \\
Tamanho & 0,31 & 0,11 & 0,07 & 0,30 & $-0,23$ & 1,00 & 0,45 \\
Massa & $-0,04$ & $-0,28$ & $-0,33$ & 0,07 & $-0,02$ & 0,45 & 1,00 \\
\hline
\end{tabular}

cos de contaminação por $\mathrm{Hg}$, ao consumirem ostras provenientes do canal de Santa Cruz, mesmo com os níveis encontrados situados abaixo do limite máximo recomendado.

Há muitos anos não é feito um monitoramento dos níveis de mercúrio no efluente da indústria de cloro, estabelecida nas proximidades do canal de Santa Cruz, pelos órgãos ambientais de Pernambuco, de forma que hoje não há informação disponível sobre os níveis atuais de Hg que estão sendo lançados no canal.

A quantidade de ostras comercializadas no Estado de Pernambuco é significativa e o ambiente, do qual elas estão sendo retiradas, se apresenta impactado por mercúrio. Um con- trole rígido deveria ser feito pelos órgãos ambientais para impedir que emissões de $\mathrm{Hg}$, acima do limite permitido pela legislação ambiental, sejam feitas devido à importância econômica e ambiental do estuário para a região.

Para uma avaliação mais completa dos riscos relacionados com a contaminação por $\mathrm{Hg}$ é necessário avaliar outras espécies de pescados e de frutos do mar provenientes do canal de Santa Cruz, e também dos níveis de mercúrio em amostras de cabelo, sangue e urina da população que vive da coleta e pesca de frutos do mar. 


\section{Referências}

ANZFA (Australia, New Zealand Food Authority), 1996. Food Standards Code. Canberra: Australia Government Publishing Service/ANZFA.

BRASIL, 2000. Lei ordinária no 9.976, de 04 de julho de 2000. Dispõe sobre a produção de cloro e dá outras providências. Diário Oficial da República Federativa do Brasil. 21 Outubro $2002<$ http:// legiferante.com/leis2000/lei9976.htm>.

BRZOSKA, M. M. \& MONIUSZKO-JAKONIUK, J., 2001. Interactions between cadmium and zinc in the organism. Food and Chemical Toxicology, 39: 967-980.

FARRINGTON, J. W.; GOLDBERG, E. D.; RISEBROUGH, R. W.; MARTIN, J. H. \& BOOWEN, V. T., 1983. U.S. Mussel Watch 1976-1978: An overview of the trace-metal, DDE, PCB, hydrocarbon and artificial radionuclide data. Environmental Science and Technology, 17:490-496.

FIEPE (Federação das Indústrias de Pernambuco), 1998. Anuário Estatístico de Pernambuco - 1998. Recife: FIEPE.

FRANCESCONI, K. A.; LENANTON, R. C. J.; CAPUTI, N. A \& JONES, N., 1997. Long-term study of mercury concentrations in fish following cessation of a mercury-containing discharge. Marine Environmental Research, 43:27-40.

GAGNON, C. \& FISHER, N. S., 1997. Bioavailability of sediment-bound methyl and inorganic mercury to a marine bivalve. Environmental Science Technology, 31:993-998.

GOLDBERG, E. D.; KOYDE, M; HODGE, V.; FLEGAL, A. R. \& MARTIN, J., 1983. U.S. Mussel Watch 1977 1978: Results on trace metals and radio nuclides. Estuarine Coastal and Shelf Science, 16:69-83.

IBAMA (Instituto Brasileiro do Meio Ambiente), 1999. Boletim Estatístico da Pesca Marítima e Estuarina do Estado de Pernambuco - 1998. Tamandaré: IBAMA.

INÁCIO, M. M.; PEREIRA, V. \& PINTO, M. S., 1998. Mercury contamination in sandy soils surrounding an industrial emission source (Estarreja, Portugal). Geoderma, 85:325-339.

JONES, G. B.; MERCURIO, P. \& OLIVIER, F., 2000. Zinc in fish, crabs, oysters, and mangrove flora and fauna from Cleveland Bay. Marine Pollution Bulletin, 41:345-352.
KAWAGUSHI, T.; PORTER, D.; BUSHEK, D. \& JONES, B., 1999. Mercury in the American oyster Crassostrea Virginica in south Carolina, USA, and public health concerns. Marine Pollution Bulletin, 38:324-327.

MERGLER, D., 2002. Review of neurobehavioral deficits and river fish consumption from the Tapajós (Brazil) and St. Lawrence (Canada). Environmental Toxicology and Pharmacology, 12:93-99.

MEYER, U., 1996. On the Fate of Mercury in the Northeastern Brazilian Mangrove System, Canal de Santa Cruz, Pernambuco. Bremen: Zentrum für Marine Tropenökologie.

NIENCHESKI, L. F.; WINDOM, H. L.; BARAJ, B.; WELLS, D. \& SMITH, R., 2001, Mercury in fish from Patos and Mirim lagoons, Southern Brazil. Marine Pollution Bulletin, 42:1403-1406.

USEPA (United States Environmental Protection Agency), 1995. National Forum on Mercury in Fish: Proceedings. Office of Water, EPA 823-R-95-002. Washington, DC: USEPA.

USEPA (United States Environmental Protection Agency), 1997. Guidance for Assessing Chemical Contaminant Data for Use in Fish Advisories. v. II Risk Assessment and Fish Consumption Limits. EPA 823-B-97-009. Washington, DC: USEPA.

WHO (World Health Organization), 2002a. Hazardous Chemicals in Human and Environmental Health. 16 August $2002<$ http://www.who.int/pcs/training _material/hazardous_chemicals/section_1.htm>.

WHO (World Health Organization), 2002b. Water and Sanitation, Mercury. 16 August $2002<\mathrm{http}$ /// www.who.int/water_sanitation_health/GDWQ/ Chemicals/mercuryfull.htm>.

WRIGHT, D. A.; MIHURSKY, J. A. \& PHELPS, H. L., 1985. Trace metals in Chesapeake Bay oysters: Intra-sample variability and its implications for biomonitoring. Marine Environmental Research, 16:181-197.

Submetido em 30 de outubro de 2002

Versão final reapresentada em 30 de maio de 2003

Aprovado em 23 de junho de 2003 